\title{
Performance Assessment of Sintered Metal Fiber Filters in Fluid Catalytic Cracking Unit
}

\author{
Liang Yang, ${ }^{1}$ Zhongli Ji, ${ }^{1}$ Qiaoqi $\mathrm{Xu},{ }^{1}$ and $\mathrm{Hao} \mathrm{Li}^{2}$ \\ ${ }^{1}$ College of Mechanical and Transportation Engineering, China University of Petroleum, Beijing 102249, China \\ ${ }^{2}$ College of Chemical Engineering, China University of Petroleum, Beijing 102249, China \\ Correspondence should be addressed to Zhongli Ji; jizhongli63@vip.sina.com
}

Received 6 June 2014; Accepted 30 June 2014; Published 16 July 2014

Academic Editor: Donald L. Feke

Copyright (c) 2014 Liang Yang et al. This is an open access article distributed under the Creative Commons Attribution License, which permits unrestricted use, distribution, and reproduction in any medium, provided the original work is properly cited.

\begin{abstract}
A long-term test was performed in a fluid catalytic cracking (FCC) hot gas filtration facility using sintered metal candle filters. The operating temperature and pressure were maximum $55^{\circ} \mathrm{C}$ and $0.28 \mathrm{MPa}$, respectively. Specific particle sampling systems were used to measure the particle size and concentration directly at high temperature. The range of inlet particle concentration is from 150 to $165 \mathrm{mg} / \mathrm{Nm}^{3}$. The outlet particle concentration is in the range of $0.71-2.77 \mathrm{mg} / \mathrm{Nm}^{3}$ in stable operation. The filtration efficiency is from $98.23 \%$ to $99.55 \%$. The inlet volume median diameter and the outlet volume median diameter of the particle are about $1 \mu \mathrm{m}$ and $2.2 \mu \mathrm{m}$, respectively. The cake thickness is calculated based on the equation of Carman-Kozeny. The effects of operating parameters including face velocity, gas cleaning pressure, pulse duration, and maximum pressure drop were investigated. The optimal operating conditions and cleaning strategies were determined. The results show that sintered metal fiber filters are suitable for industrial application due to the good performance and high efficiency observed.
\end{abstract}

\section{Introduction}

Hot gas filtration from industrial processes offers various advantages in terms of improvement of process efficiency, heat recovery, and protection of plant installation. Particularly, hot gas filtration is an essential technology for pressurized fluidized bed combustion (PFBC) and integrated gasification combined cycle (IGCC), promising coal fired generation of electricity with substantially greater thermodynamic efficiencies and reduced particulate pollutant emissions [14]. The filtration can protect gas turbine blades from the erosion and corrosion and improve the performance of a heat exchanger connected to a steam turbine by decreasing particles deposition.

Initially, the combined cycle power generation mentioned above has driven this development, but the focus now is shifted to the chemical and process industries. Fluid catalytic cracking (FCC) is a process for converting high molecular weight into light and getting high valuable hydrocarbons through contact with a powdered catalyst at appropriate process conditions [5-7]. Basically, the FCC process includes two sections. One section is used for the cracking to take place on contact with hot catalyst particles at approximately $520^{\circ} \mathrm{C}$, and another section is designed for the regeneration of the catalyst at approximately $720^{\circ} \mathrm{C}$, where the carbon deposit is reduced from $1-2 \mathrm{wt} \%$ to $0.05-0.2 \mathrm{wt} \%$ by burning in air which is fed into the regenerator at about $0.3 \mathrm{MPa}$. In a gascatalytic reaction, the major purpose of hot gas filtration is to recover waste heat and reduce particle release. In addition, the hot gas filtration can protect the downstream equipment and meet environmental standards. In gas-solid reactions, the gas must be thoroughly cleaned in order to avoid turbine blade damage, and there is a strong thermal advantage for gas turbine power generation.

It is highly required to develop new materials and advanced operating strategies for FCC process at high temperatures. Ceramic filter is one of the most promising hot gas filtration techniques. However, due to the limitations on design and materials, long-term operation of ceramic filters is still not very successful [8]. There are some fundamental limitations due to the intrinsic material properties, which have to be improved [9]. The unreliability of the ceramic filters in demonstration trials has hindered their application [10]. Sintered metal fiber filters have been successfully used in hot 


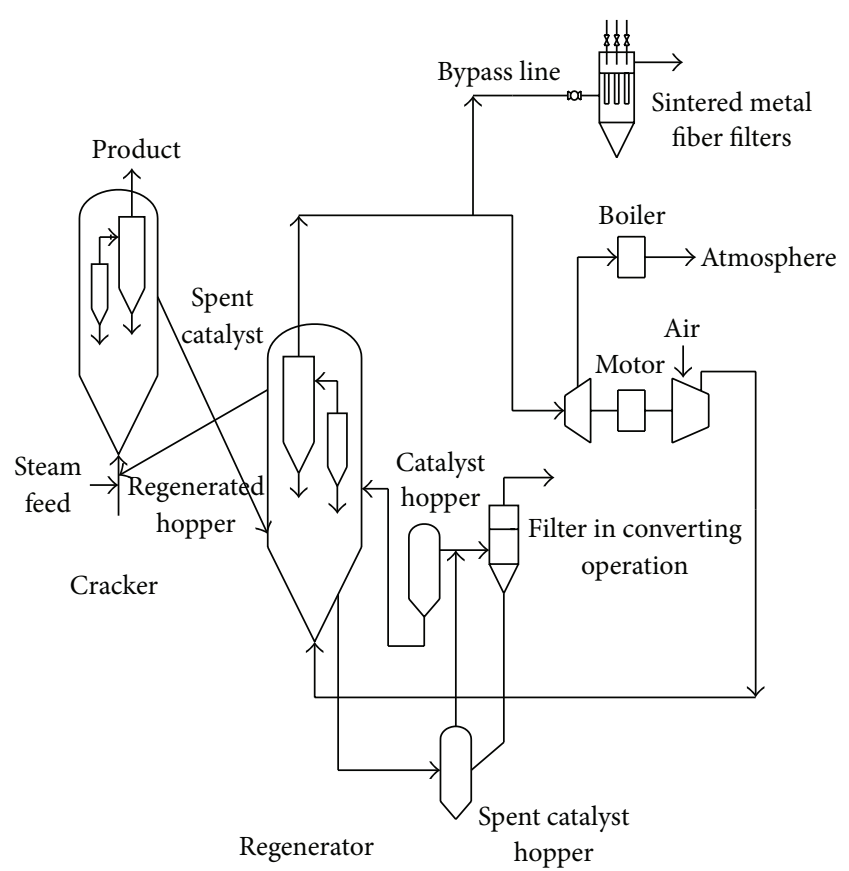

FIgUre 1: A typical layout of a FCC unit and the location of hot gas filtration facility.

gas systems for many years [11]. They have also been used for hot gas filtration in various plants due to their characteristics of fracture toughness, high thermal shock resistance, and long service life [12].

The aim of this research is to evaluate the performance of high temperature sintered metal fiber filters under a variety of operating conditions in a FCC hot gas filtration facility. The effects of operating parameters were investigated in order to determine the optimal operating conditions and cleaning strategies.

\section{Materials and Methods}

2.1. Experimental Facility. A typical layout of a FCC unit and the location of hot gas filtration facility are illustrated in Figure 1. The fluidizing velocity is very high and close to the terminal velocity of the catalyst in both the reactor and regenerator bed. At this high velocity, the exhaust gas elutriates fine particles. The output of the reactor is fed to a battery of primary and secondary cyclones, connected in series, and positioned within the reactor vessel. These cyclones return the catalyst to the reactor bed.

A schematic diagram of the hot gas filtration facility is illustrated in Figure 2. The main operating parameters and composition of the FCC dusty gas are summarized in Table 1. More than 7000-hour continuous test was performed during the research. The major parts of the facility include the filtration unit with pulse cleaning, particle sampling system, and data acquisition system. The facility was designed for the maximum operating temperature of $800^{\circ} \mathrm{C}$. By changing the thickness of insulation layer outside the filter vessel,
TABLE 1: Main operating parameters and composition of the FCC dusty gas.

\begin{tabular}{|c|c|c|}
\hline \multicolumn{3}{|c|}{ Main operating parameters } \\
\hline FCC dusty gas flow rate & \multicolumn{2}{|c|}{$10-100 \mathrm{Nm}^{3} / \mathrm{h}$} \\
\hline Operating temperature & \multicolumn{2}{|c|}{$200-550^{\circ} \mathrm{C}$} \\
\hline Operating pressure & \multicolumn{2}{|c|}{$0.28 \mathrm{MPa}$} \\
\hline Cleaning gas & \multicolumn{2}{|c|}{ Nitrogen } \\
\hline Gas cleaning temperature & \multicolumn{2}{|c|}{$250^{\circ} \mathrm{C}$} \\
\hline Gas cleaning pressure & \multicolumn{2}{|c|}{$0.3-0.7 \mathrm{MPa}$} \\
\hline Pulse duration & \multicolumn{2}{|c|}{$120-350 \mathrm{~ms}$} \\
\hline Maximum pressure drop & \multicolumn{2}{|c|}{$2-6 \mathrm{kPa}$} \\
\hline \multicolumn{3}{|c|}{ Composition of the FCC dusty gas } \\
\hline $\mathrm{O}_{2} 4.15 \%$ & $\mathrm{CO}_{2} 9.55 \%$ & CO 3 ppm \\
\hline NO 128 ppm & $\mathrm{NO}_{2} 0.8 \mathrm{ppm}$ & $\mathrm{NO}_{X} 129 \mathrm{ppm}$ \\
\hline $\mathrm{SO}_{2} 20 \mathrm{ppm}$ & $\mathrm{H}_{2} 3 \mathrm{ppm}$ & $\mathrm{H}_{2} \mathrm{~S} 6.4 \mathrm{ppm}$ \\
\hline Dew point of FCC dusty gas & \multicolumn{2}{|c|}{$86.3^{\circ} \mathrm{C}$} \\
\hline
\end{tabular}

the operating temperature can be controlled at the required temperature level.

The filter vessel is a stainless steel cylindrical column with $360 \mathrm{~mm}$ diameter, $3300 \mathrm{~mm}$ height, and a conical base. The vessel was designed to accept three candle filters with $60 \mathrm{~mm}$ outer diameter and $600 \mathrm{~mm}$ overall length. Each filter is suspended vertically at a tube plate with $415 \mathrm{~mm}$ diameter and $20 \mathrm{~mm}$ thickness. An overall view of the filter vessel is given in Figure 3. The FCC stream from regenerator can be entered into the test facility vessel from the bypass line through a $50 \mathrm{~mm}$ diameter pipe with its centre line approximately $0.2 \mathrm{~m}$ below the tube plate. A specific gas distributor has been designed for mixing dusty gas well. A diffuse plate is placed in the front of the inlet to avoid direct impact of dusty gas on the filers. A hopper is used to collect and discharge the particles accumulated at the bottom of the filter vessel.

Compressed nitrogen gas in the pressure range of $0.3-$ $0.7 \mathrm{MPa}$ is used for gas cleaning. The pulse cleaning duration is controlled by three solenoid valves mounted above the filter vessel. Each solenoid valve is connected to a nozzle which is directed vertically downward into a venturi injector mounted on top of the filter. The injector can also serve as a counterweight and compresses the gasket between the filter top and tube plate. The temperature of the compressed nitrogen gas was kept at about $250^{\circ} \mathrm{C}$ using an electronic heater to prevent condensation during the pulse cleaning. The frequency of pulse cleaning was automatically controlled by pressure in the way that the cleaning system is activated when a predetermined pressure drop is reached. The facility was connected with a computer so that the operating parameters of the system can be logged into the computer and continuously monitored during the tests.

2.2. Candle Filters. The filter elements tested during this study are sintered metal fiber filters manufactured by Bekaert Corporation. The dimensions of the filter are $60 \mathrm{~mm}$ outer diameter, $50 \mathrm{~mm}$ internal diameter, and $600 \mathrm{~mm}$ total length with $8 \mathrm{~mm}$ neck for the fixation to the tube plate. The effective 


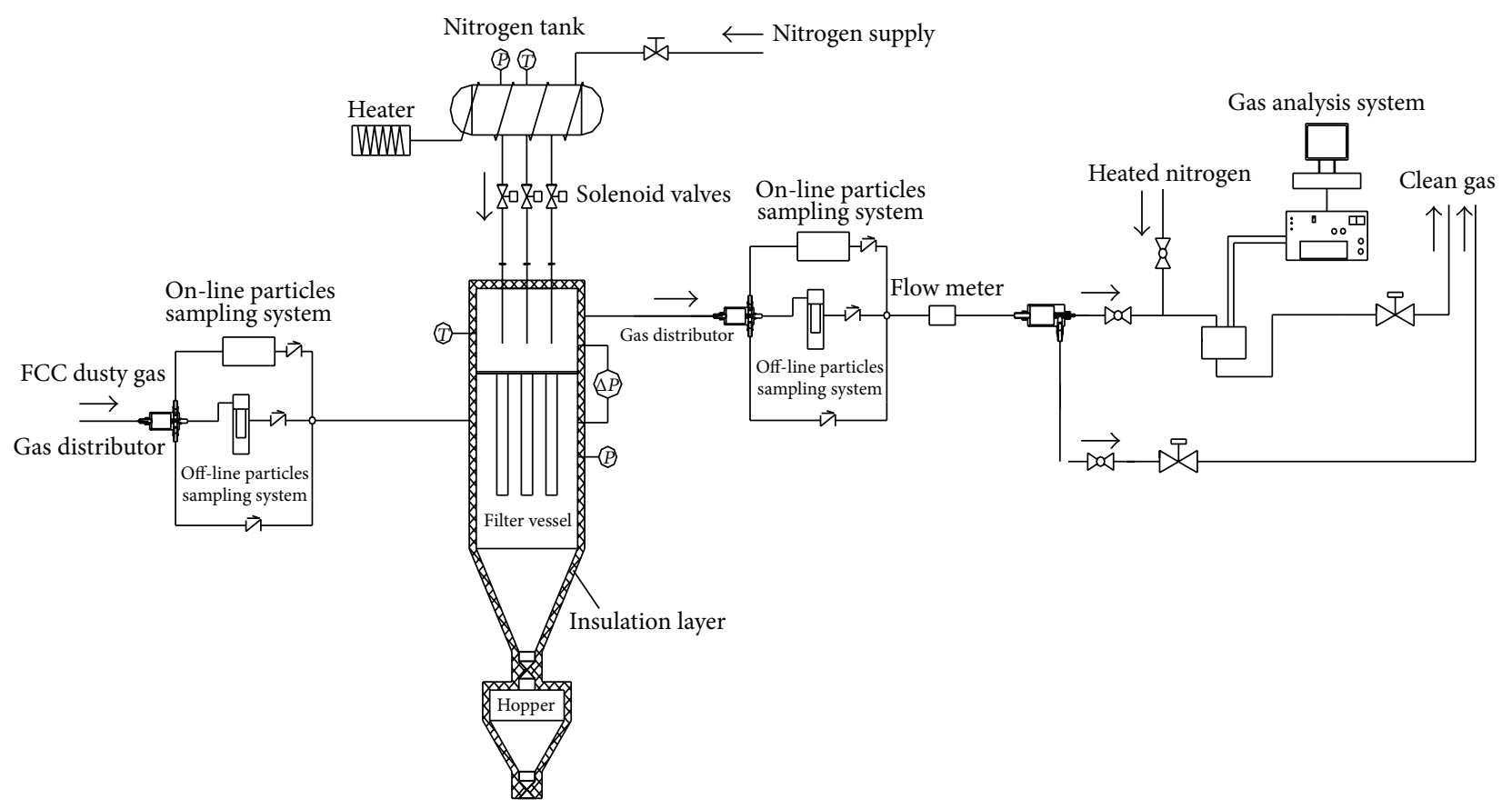

FIGURE 2: Schematic diagram of the hot gas filtration facility.

filtration area is $0.113 \mathrm{~m}^{2}$ for each candle filter. The porosity is about $85 \%$ and the diameters of pores are between 10 and $60 \mu \mathrm{m}$. The density of the filters is about $1650 \mathrm{~kg} / \mathrm{m}^{3}$. The filters that are fabricated from AISI 430 stainless steel can resist high temperature at $1000^{\circ} \mathrm{C}$.

2.3. Particle Sampling System. The particle sampling system consists of an off-line particle sampling system and an on-line particles sampling system. The two systems have been specifically designed with the aim of determining the particles concentration and particle size distribution (PSD) prior to and after the filtration vessel. The particle sampling system was specifically developed and can be used under the maximum temperature of $650^{\circ} \mathrm{C}$.

The main part of the off-line particle sampling system is a sintered metal filter tube with high efficiency of $99.9 \%$ for removing $0.3 \mu \mathrm{m}$ particles. The temperature of the particle sampling system can be controlled above $180^{\circ} \mathrm{C}$ by electronic heater to avoid condensation inside the sintered metal filter tube. The weight of the particles remaining in the filter tube is determined by weighing the filter tube before and after sampling. The filtration efficiencies reported below are based on the inlet gas concentrations, gas flow rate duration of sampling, and the changes in the weight of the filter tube. The online particle sampling system uses an intense source of white light to illuminate a nearly cubic particle sensing volume of located at the centre of the aerosol flow path. This volume is defined by a combination of apertures placed in the optical path of the illumination and the two sensing branches, which are arranged at an observation angle of $90^{\circ}$ opposing each other [13]. The principle and more details of the on-line particles sampling system can be found in our previous research [14].

\section{Results and Discussion}

3.1. Initial and Residual Pressure Drop. The initial pressure drop is defined as variation of the pressure drop across filters with the face velocity by considering clean gas through them. The influence of the temperature and face velocity on the pressure drop across the filters can be investigated during these tests.

Figure 4 shows the evolution of the initial pressure drop with the face velocity at five temperature levels: $305^{\circ} \mathrm{C}, 365^{\circ} \mathrm{C}$, $425^{\circ} \mathrm{C}, 495^{\circ} \mathrm{C}$, and $550^{\circ} \mathrm{C}$, respectively. It can be observed that the pressure drop increases approximately linearly with the face velocity, as Darcy's Law indicates. When the operating temperature increases from $305^{\circ} \mathrm{C}$ to $550^{\circ} \mathrm{C}$, the pressure drop increases for the same face velocity values; this phenomenon is mainly due to the rise of the gas viscosity with temperature.

One of the parameters which can be used to measure the influence of the operating time is the residual pressure drop. Figure 5 shows the variations of pressure drop along the operating time of filtration. The initial pressure drop is about $0.85 \mathrm{kPa}$. When the pressure drop approaches $2 \mathrm{kPa}$, the filters are cleaned by pulse cleaning and the pressure drop is reduced nearly to the initial. However, the particles collected on the filters cannot be removed completely. Some particles remain in the filters; therefore, the pressure drop is not recovered to the initial and a residual pressure drop is generated. The possible reason is that the fine particles which have been collected deeply into the filter pores are difficult to be detached. As the pulse cleaning is repeated, the residual pressure drop increases and becomes over $1.1 \mathrm{kPa}$ after the operating time of $120 \mathrm{~h}$. Figure 6 shows the change of residual pressure drop with the filtration time. It can be observed that the residual pressure drop increases significantly at 


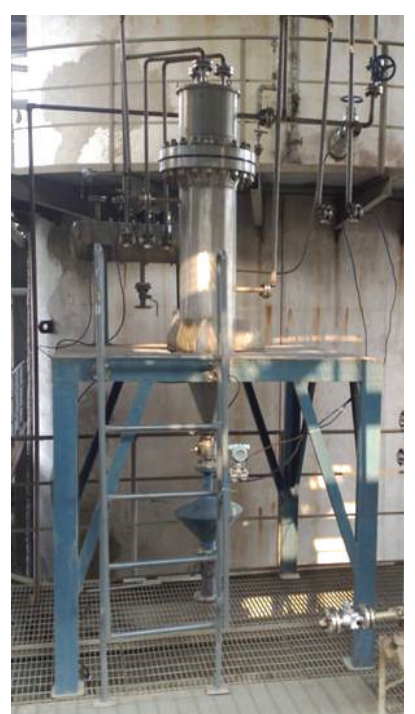

(a)

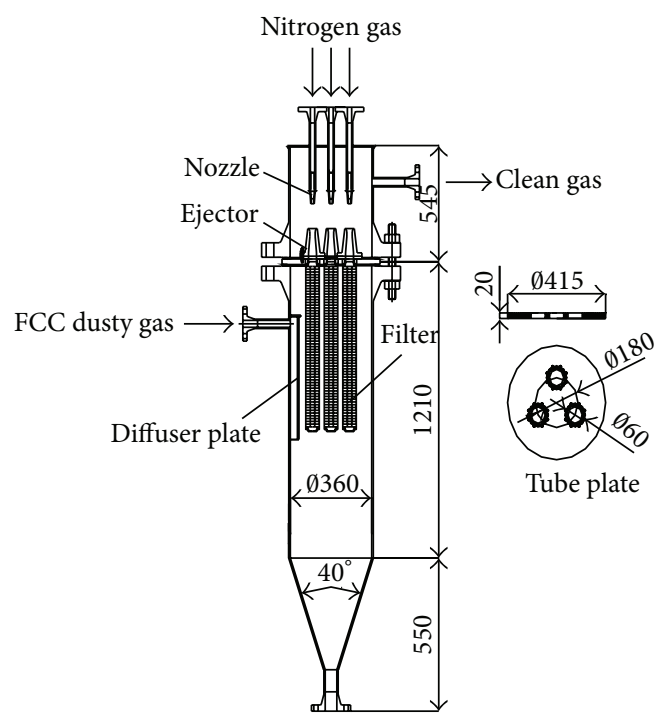

(b)

FIGURE 3: Overall view of the filter vessel.

the operating time of $0-720 \mathrm{~h}$. After $720 \mathrm{~h}$, the residual pressure drop keeps stable at about $1.35 \mathrm{kPa}$.

3.2. Catalyst Particle Properties. Scanning electron microscopy (SEM) was used to observe the microstructure of catalyst particles. The SEM pictures are shown in Figure 7. The relative percentage of elements of the catalyst particle is measured by Energy Dispersive X-Ray Spectrum (EDX). Figure 8 and Table 2 show the EDX measured results. The particle size distribution (PSD) in the off-line particle system is determined by a Coulter counter analyzer (Coulter Multisizer 3). The results are shown in Figure 9. The PSD results measured by the on-line particle system are given in Figure 10.

It can be observed from Figure 7 that the inlet particles show a good spherical shape. The inlet volume median

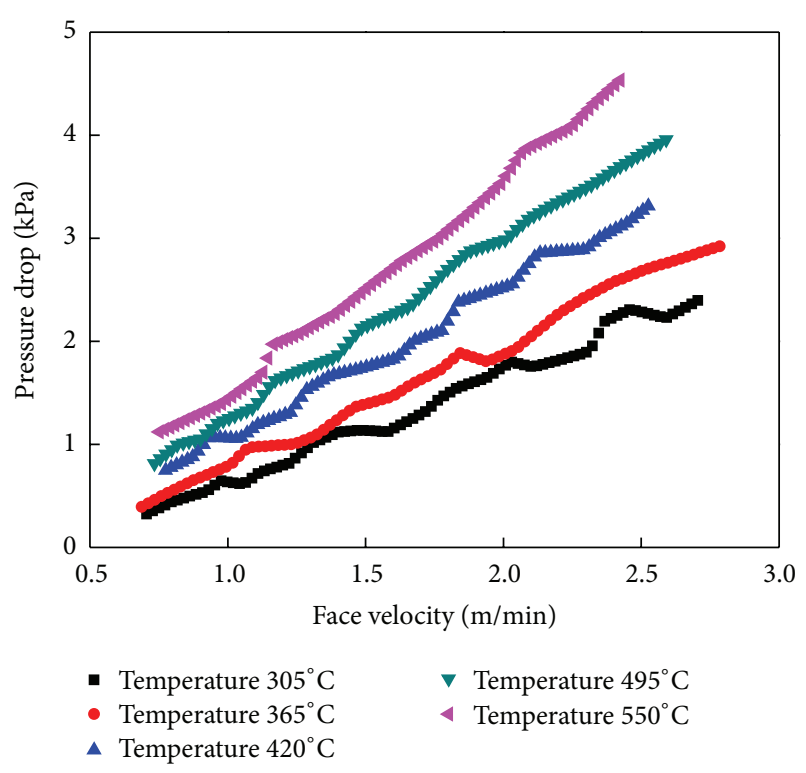

FIGURE 4: Evolution of the initial pressure drop with the face velocity at five temperature levels.

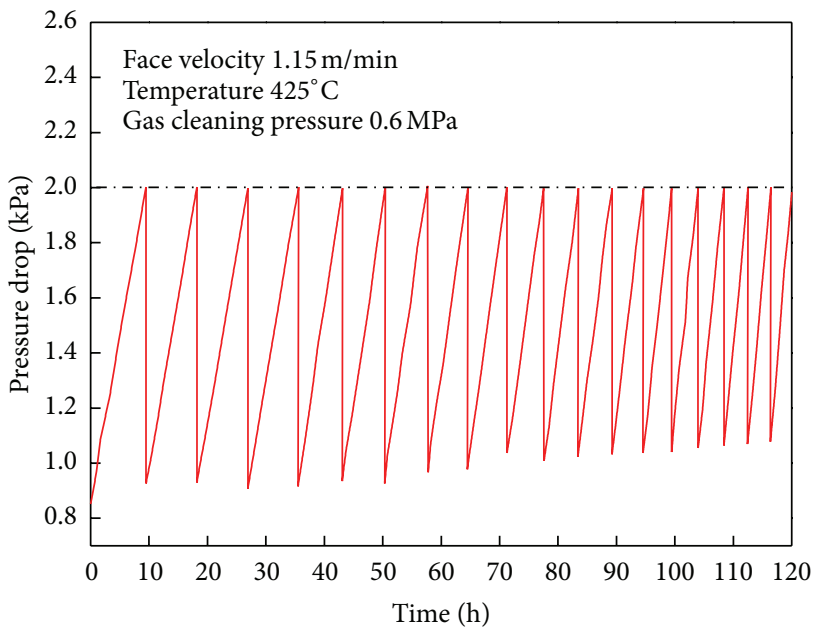

FIGURE 5: The variations of pressure drop during operation.

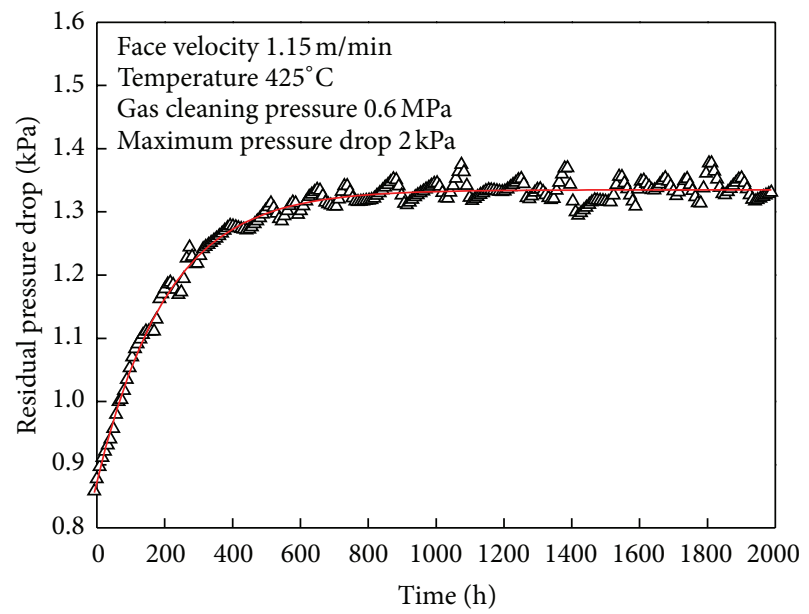

FIGURE 6: The variations of residual pressure drop during operation. 


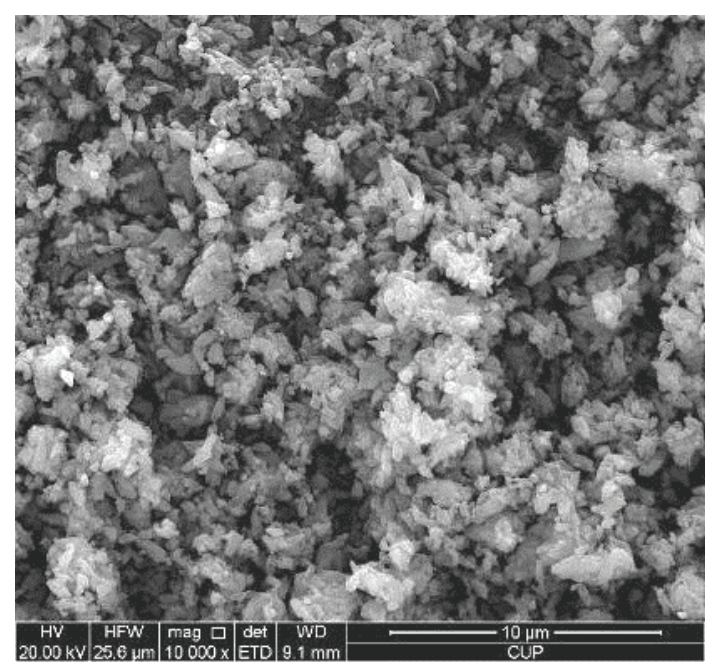

(a)

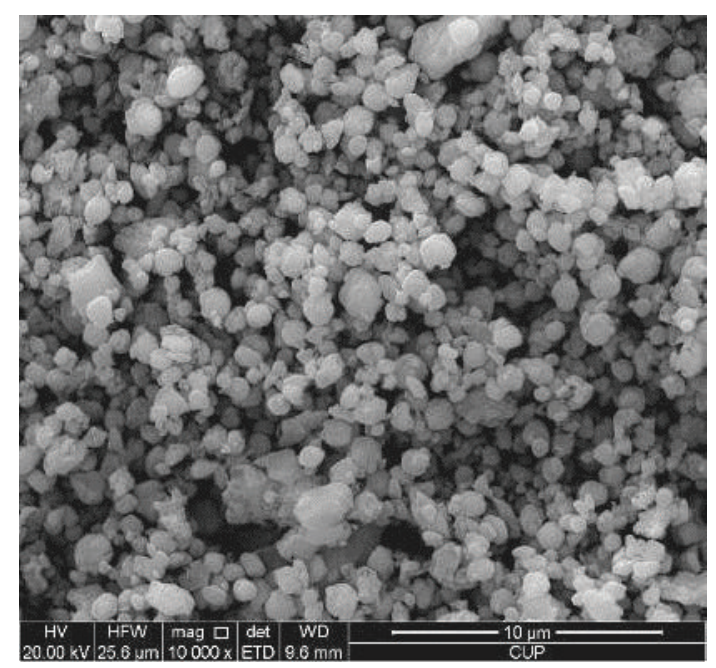

(b)

FIGURE 7: SEM of the catalyst particle ((a) is the outlet particle and (b) is the inlet particle).

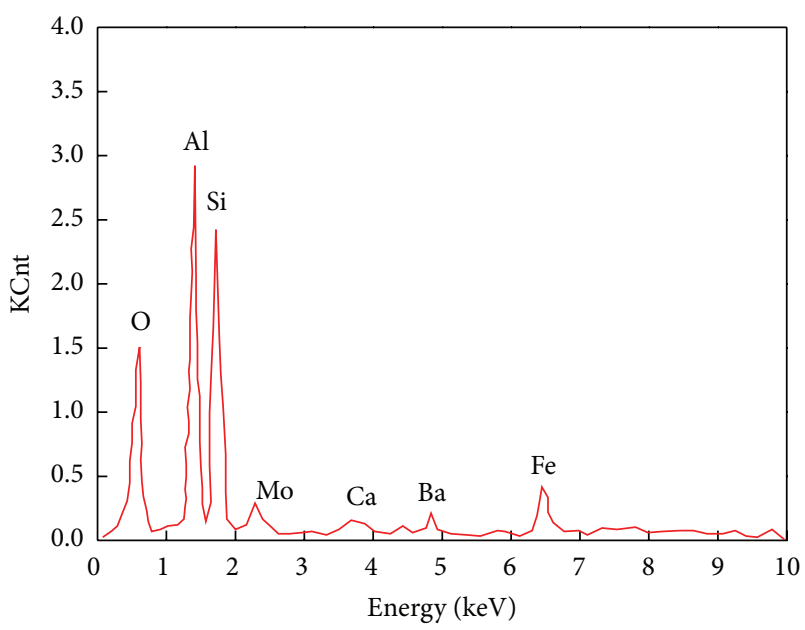

FIGURE 8: The image of EDX measured results.

diameter and the outlet volume median diameter of the particles measured by the off-line particle sampling system are about $1.14 \mu \mathrm{m}$ and $2.37 \mu \mathrm{m}$, respectively. The inlet volume median diameter and the outlet volume median diameter of the particles measured by the on-line particle sampling system are about $0.92 \mu \mathrm{m}$ and $2.21 \mu \mathrm{m}$, respectively. The results measured by off-line particle sampling system agree well with those measured by on-line particle sampling system.

3.3. Filtration Efficiency. A peak emission is found after each pulse cleaning during an unstable operation, and a typical emission profile is illustrated in Figure 11. However, the emission phenomenon disappeared after the 100th cycle. During pulse cleaning, it is found that the outlet particle concentration increases rapidly. The outlet particle concentration changes from $16.25 \mathrm{mg} / \mathrm{Nm}^{3}$ to $37.55 \mathrm{mg} / \mathrm{Nm}^{3}$ during the pulse cleaning. This phenomenon could be caused by several
TABLE 2: The relative percentage of elements of the catalyst particle.

\begin{tabular}{lll}
\hline Element & Wt $/ \%$ & At $/ \%$ \\
\hline OK & 36.54 & 52.45 \\
$\mathrm{AlK}$ & 23.97 & 20.40 \\
$\mathrm{SiK}$ & 28.99 & 23.71 \\
$\mathrm{MoL}$ & 02.49 & 00.60 \\
$\mathrm{CaK}$ & 01.04 & 00.60 \\
$\mathrm{BaL}$ & 02.50 & 00.42 \\
$\mathrm{FeK}$ & 04.47 & 01.84 \\
\hline
\end{tabular}

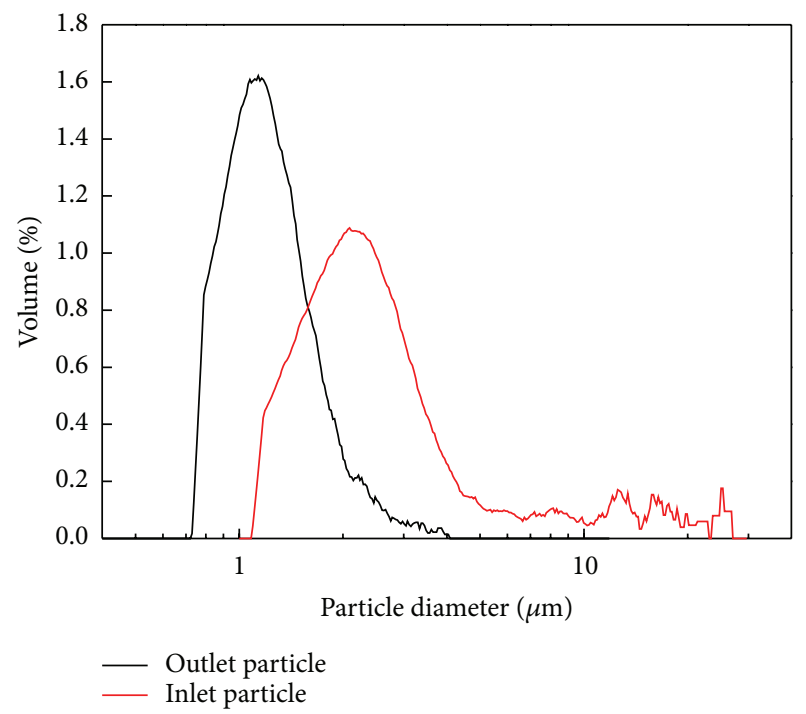

FIGURE 9: PSD measured by the Coulter counter analyzer.

mechanisms such as the decrease of filtration efficiency due to the dust cake detachment, the particle penetration through the filter media due to the pulse cleaning shock, or the direct 


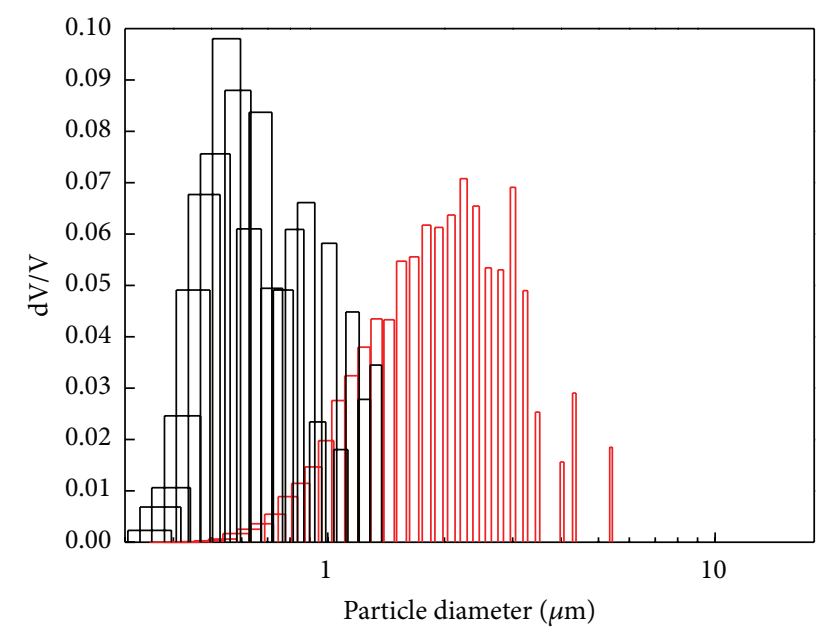

Inlet particle Outlet particle

FIGURE 10: PSD measured by the on-line particle sampling system.

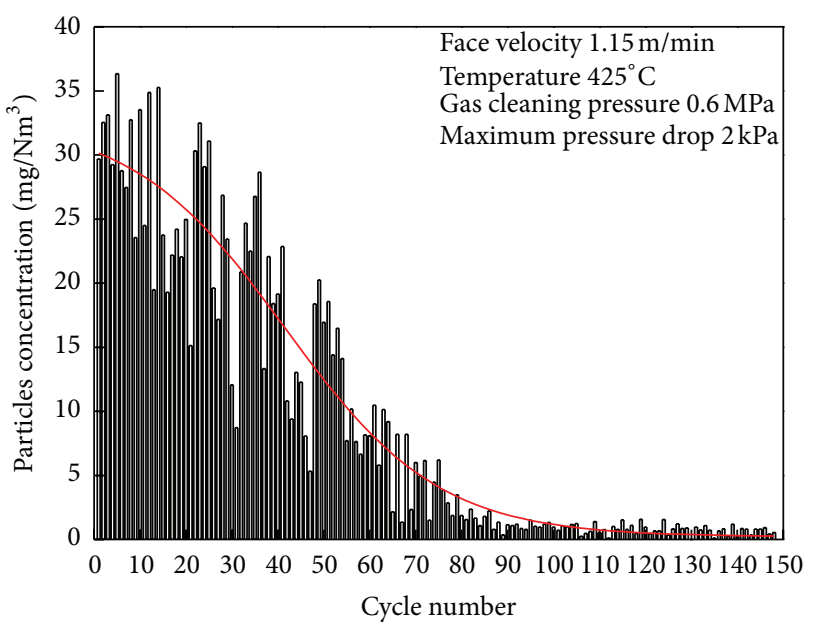

FIGURE 11: Typical particles emission profile during operation.

particle penetration through the filters [15-17]. One of the reasons for this problem may be the serious gas reflux from outside to inside of filters during pulse cleaning. The reflux causes fine particles to redeposit on outer surface of the filters or even penetrate into the filters. However, due to the formation of a constant and dense residual dust cake layer on the filters surface, the emission peaks progressively decrease. This residual dust cake layer dominates the subsequent filtration and stable operation.

When the filters are in stable operation, the filtration efficiencies can be measured at three face velocities $(1.15 \mathrm{~m} / \mathrm{min}$, $1.5 \mathrm{~m} / \mathrm{min}$, and $2.2 \mathrm{~m} / \mathrm{min}$ ) and three temperatures $\left(305^{\circ} \mathrm{C}\right.$, $425^{\circ} \mathrm{C}$, and $550^{\circ} \mathrm{C}$ ). The maximum pressure drop is $2 \mathrm{kPa}$ and the gas cleaning pressure is $0.6 \mathrm{MPa}$. The test results of particle concentration and filtration efficiency are listed in Table 3. A significant effect of temperature on the filtration efficiency cannot be observed during these tests. The inlet particle average concentration range is from 150 to $165 \mathrm{mg} / \mathrm{Nm}^{3}$. The outlet particle average concentration is in the range of 0.71$2.77 \mathrm{mg} / \mathrm{Nm}^{3}$. Slower pressure drop building up during the filtration, which results in longer pulse cleaning intervals, was one of the reasons for the higher filtration efficiencies. The filtration efficiency decreases from $99.55 \%$ to $98.23 \%$ when the face velocity is increased from $1.15 \mathrm{~m} / \mathrm{min}$ to $2.2 \mathrm{~m} / \mathrm{min}$. The decrease in the filtration efficiency is associated with an increase in the pulse cleaning frequency, which could eventually result in a thinner dust cake and poorer filtration.

3.4. Dust Cake Thickness. Since it is difficult to measure the cake thickness directly, the cake thickness is estimated from the measured increase of pressure drop across the dust cake using the well-known equation of Carman-Kozeny [18], which is applied to the laminar flow conditions $(\operatorname{Re}<1)$, giving

$$
h=\frac{\left(\Delta P_{\text {cake }} \varphi^{2} d_{v}^{2} \varepsilon^{3}\right)}{\left[C \mu(1-\varepsilon)^{2} U\right]},
$$

where $h$ is the dust cake thickness, $\Delta P_{\text {cake }}$ is the pressure drop across the dust cake, $\varphi$ is the particle sphericity, $d_{v}$ is the diameter of an ideal sphere having the same volume as the particles in the experiment, $\varepsilon$ is the cake porosity, $C$ is the Carman-Kozeny constant $(C=180), \mu$ is dynamic viscosity of gas at filter's operating temperature, and $U$ is face velocity. Particle diameter of $2.4 \mu \mathrm{m}$ and particle sphericity of 0.87 (observed from the SEM image of Figure 7) are used for dust cake. The cake porosity was estimated from experimental investigations by Schmidt on dust cakes deposited on filter media [19]. Schmidt reported that, for limiting pressure drops of $0.5,1$, and $2 \mathrm{kPa}$, the dust cake porosity ranged from $85 \%$ at the cake surface to $68 \%$ at the filter surface. In this research, a cake porosity of $80 \%$ was used to estimate the cake thickness. Depending on the maximum pressure drop and the face velocity, the estimated cake thickness is in the range of $0.43-$ $4.15 \mathrm{~mm}$. The estimated cake thickness can be used to determine the cake mass as well as the percentage of dust attached to the filters. The cake mass can be calculated from the equation below:

$$
m_{\text {cake }}=\rho_{B} L\left[\pi\left(R_{i}+h\right)^{2}-\pi R_{i}^{2}\right],
$$

where $m_{\text {cake }}$ is the cake mass, $\rho_{B}$ is the bulk density of the particles, $L$ is the effective candle filter length, and $R_{i}$ is the outer radius of the clean filter.

The operating temperature is $425^{\circ} \mathrm{C}$, the gas cleaning pressure is $0.6 \mathrm{MPa}$, and the inlet particles concentration is approximately $160 \mathrm{mg} / \mathrm{Nm}^{3}$. The bulk density of the particles is approximately $730 \mathrm{~kg} / \mathrm{m}^{3}$. The results indicate that the percentage of particles attached on filters was in the range of 65$90 \%$. At a face velocity of $2.2 \mathrm{~m} / \mathrm{min}$, nearly $86 \%$ particles can be attached to the filters. Dust cake thicknesses estimated and pressure drop across the cake are summarized in Table 4.

\subsection{Effect of the Operational Parameters}

3.5.1. Face Velocity. The pressure drop across the filters was primarily affected by the face velocity. Figures 12 and 13 show 
TABLE 3: Test results of particles concentration and filtration efficiency.

\begin{tabular}{|c|c|c|c|c|}
\hline $\begin{array}{l}\text { Face } \\
\text { velocity } / \mathrm{m} / \mathrm{min}\end{array}$ & Temperature $/{ }^{\circ} \mathrm{C}$ & $\begin{array}{c}\text { Inlet particles } \\
\text { concentration } / \mathrm{mg} / \mathrm{Nm}^{3}\end{array}$ & $\begin{array}{c}\text { Outlet particles } \\
\text { concentration } / \mathrm{mg} / \mathrm{Nm}^{3}\end{array}$ & $\begin{array}{c}\text { Filtration } \\
\text { efficiency } / \%\end{array}$ \\
\hline \multirow{3}{*}{1.15} & 305 & 162.65 & 1.24 & 99.23 \\
\hline & 425 & 155.76 & 1.02 & 99.34 \\
\hline & 550 & 159.43 & 0.71 & 99.55 \\
\hline \multirow{3}{*}{1.5} & 305 & 158.32 & 1.23 & 99.22 \\
\hline & 425 & 152.45 & 1.13 & 99.26 \\
\hline & 550 & 161.23 & 1.37 & 99.15 \\
\hline \multirow{3}{*}{2.2} & 305 & 156.54 & 2.77 & 98.23 \\
\hline & 425 & 163.42 & 2.35 & 98.56 \\
\hline & 550 & 153.25 & 2.02 & 98.68 \\
\hline
\end{tabular}

TABLE 4: Dust cake thicknesses estimated and pressure drop across the cake.

\begin{tabular}{|c|c|c|c|c|c|}
\hline $\begin{array}{l}\text { Maximum pressure } \\
\text { drop } / \mathrm{kPa}\end{array}$ & $\begin{array}{c}\text { Face } \\
\text { velocity } / \mathrm{m} / \mathrm{min}\end{array}$ & $\begin{array}{c}\text { Pressure drop } \\
\text { across cake/kPa }\end{array}$ & $\begin{array}{l}\text { Estimated cake } \\
\text { thickness } / \mathrm{mm}\end{array}$ & $\begin{array}{c}\text { Estimated cake } \\
\text { mass/g }\end{array}$ & $\begin{array}{l}\text { Dust attached to } \\
\text { filters/\% }\end{array}$ \\
\hline \multirow{3}{*}{3.5} & 1.15 & 2.06 & 1.75 & 68.74 & 65 \\
\hline & 1.5 & 1.56 & 1.32 & 54.23 & 72 \\
\hline & 2.2 & 0.37 & 0.43 & 28.69 & 78 \\
\hline \multirow{3}{*}{4.2} & 1.15 & 2.79 & 3.04 & 97.65 & 68 \\
\hline & 1.5 & 2.28 & 2.37 & 85.22 & 78 \\
\hline & 2.2 & 1.12 & 1.21 & 60.37 & 81 \\
\hline \multirow{3}{*}{5.0} & 1.15 & 3.52 & 4.15 & 129.05 & 71 \\
\hline & 1.5 & 3.04 & 3.32 & 110.24 & 82 \\
\hline & 2.2 & 1.83 & 1.43 & 78.56 & 86 \\
\hline
\end{tabular}

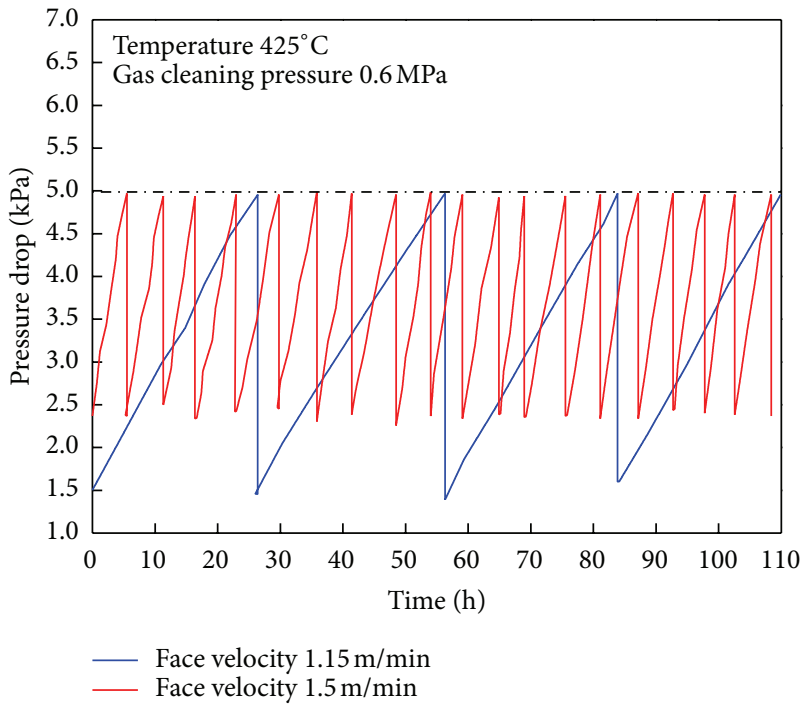

FIGURE 12: Pressure drop variations for face velocities of $1.15 \mathrm{~m} / \mathrm{min}$ and $1.5 \mathrm{~m} / \mathrm{min}$.

the pressure drop variations as a function of time for face velocities of $1.15,1.5,2.2$, and $2.55 \mathrm{~m} / \mathrm{min}$. The maximum pressure drop was set at $5 \mathrm{kPa}$ during these tests. At a face velocity of $1.15 \mathrm{~m} / \mathrm{min}$, it took about $28 \mathrm{~h}$ for the pressure drop to build from the initial to the maximum pressure drop. The

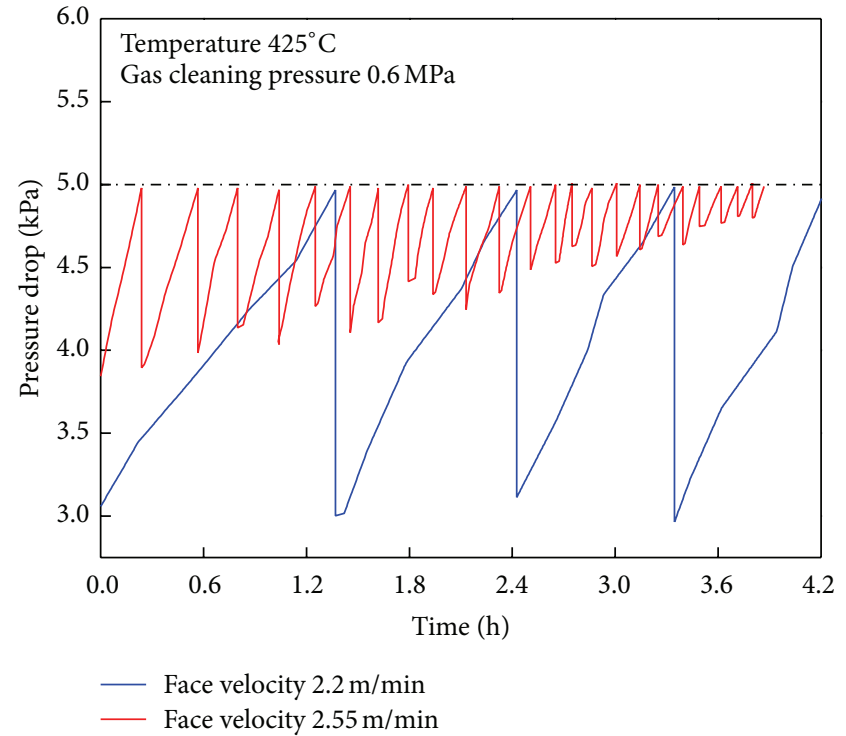

FIgURE 13: Pressure drop variations for face velocities of $2.2 \mathrm{~m} / \mathrm{min}$ and $2.55 \mathrm{~m} / \mathrm{min}$.

reasons for the extremely slow increase in the pressure drop include the high bulk density of the catalyst particles, the low inlet particle concentration, and the relatively smooth and slippery surfaces of the filters, which lead to a weak 


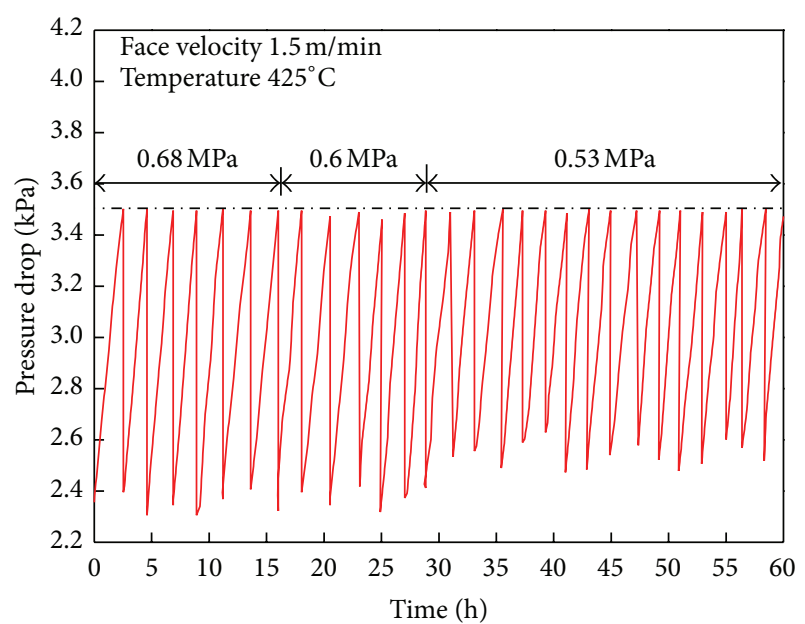

FIGURE 14: Pressure drop variations for gas cleaning pressure of $0.68 \mathrm{MPa}, 0.6 \mathrm{MPa}$, and $0.53 \mathrm{MPa}$.

adhesion of the dust cake to the filters. Similar behaviour can be observed for the face velocity of $1.5 \mathrm{~m} / \mathrm{min}$ and $2.2 \mathrm{~m} / \mathrm{min}$, and it can be observed that operation is stable when filtration velocity is from $1.15 \mathrm{~m} / \mathrm{min}$ to $2.2 \mathrm{~m} / \mathrm{min}$. However, unstable operation occurs at the face velocity of $2.55 \mathrm{~m} / \mathrm{min}$. During the unstable operation illustrated in Figure 13, a rapid increase in the pressure drop across the filters can be found and the slope of initial pressure drop increases continuously, leading to an unstable operation and more frequent pulse cleaning and determining a maximum value for the face velocity that should not be overcome.

3.5.2. Gas Cleaning Pressure. Four different gas cleaning pressures are tested under the same operating conditions. Figures 14 and 15 present the effect of the gas cleaning pressure on the pressure drop evolution. However, it must be pointed out that an upper limit of pressure cleaning can be determined, from which the frequency of the pulse remains constant despite an increase in the cleaning pressure. The improvement of pressure drop, using a cleaning pressure higher than $0.6 \mathrm{MPa}$, was not very significant; therefore, cleaning pressure value of $0.6 \mathrm{MPa}$ was selected for the tests so as to minimize the consumption of nitrogen. A lower limit of gas cleaning pressure was also determined, below which the operation was not feasible. It can be observed that the operation is not stable when gas cleaning pressure is lower than $0.45 \mathrm{MPa}$. The efficient gas cleaning pressure value depends on the operating conditions but it is normally about twice the pressure value inside the filter vessel.

3.5.3. Pulse Duration. Figure 16 shows the results of pressure drop variations measured at different duration times of the cleaning pulse, including $180 \mathrm{~ms}, 240 \mathrm{~ms}$, and $300 \mathrm{~ms}$. It can be found that the long pulse duration values of $240 \mathrm{~ms}$ and $300 \mathrm{~ms}$ do not show a significant effect on the pressure drop compared with the short pulse duration of $180 \mathrm{~ms}$.

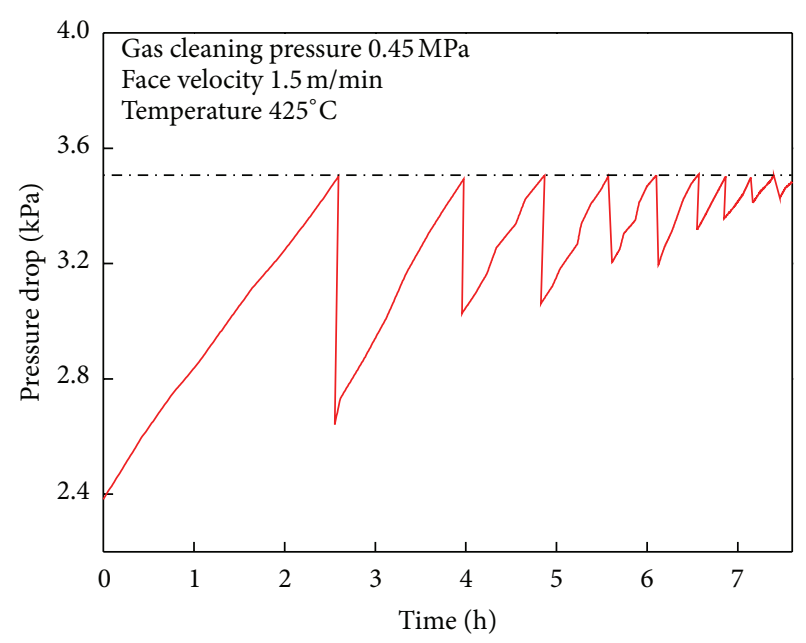

FIgURE 15: Pressure drop variations for gas cleaning pressure of $0.45 \mathrm{MPa}$.

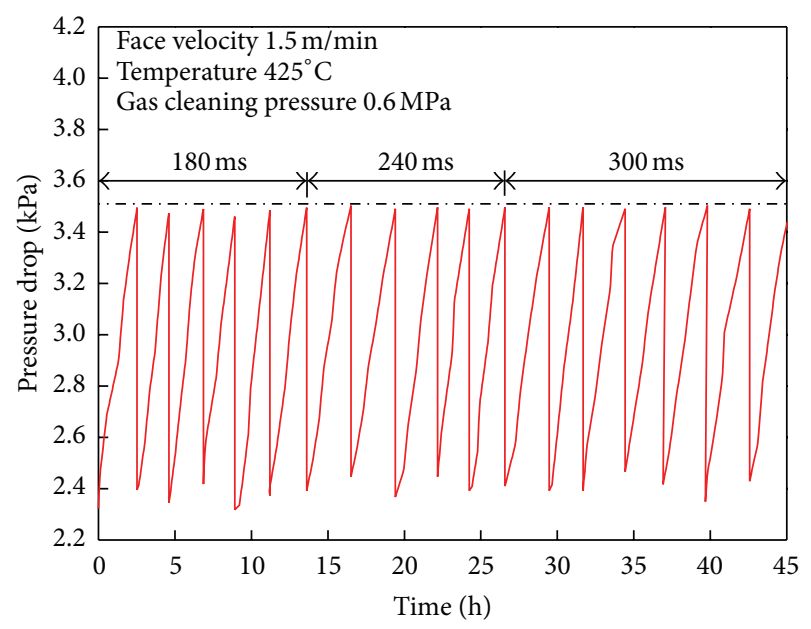

Figure 16: Pressure drop variations for pulse durations of $180 \mathrm{~ms}$, $240 \mathrm{~ms}$, and $300 \mathrm{~ms}$.

3.5.4. Maximum Pressure Drop. Figure 17 shows the results of pressure drop variations as a function of time for three different maximum pressure drops at a face velocity of $1.5 \mathrm{~m} / \mathrm{min}$. In Figure 17, it can be seen that stable operation is possible at three values of maximum pressure drop. For maximum pressure drop values of $3.5 \mathrm{kPa}$ and $4.2 \mathrm{kPa}$, both initial pressure drop remained constant and the same to each other. But for the maximum pressure drop of $2.8 \mathrm{kPa}$, the initial pressure drop is higher than those of the other two values. The reason for this phenomenon is that the lower maximum pressure drop results in a thin dust cake thickness which decreases the pulse cleaning efficiency. The frequency of the pulse cleaning decreases with increasing the level of maximum pressure drop. The pulse interval increased from $3 \mathrm{~h}$ to $5 \mathrm{~h}$ when the maximum pressure drop was increased from $3.5 \mathrm{kPa}$ to $4.2 \mathrm{kPa}$. Thus, a $40 \%$ reduction of pulse cleaning interval can be achieved by the higher value of maximum pressure drop. However, serious deterioration of 


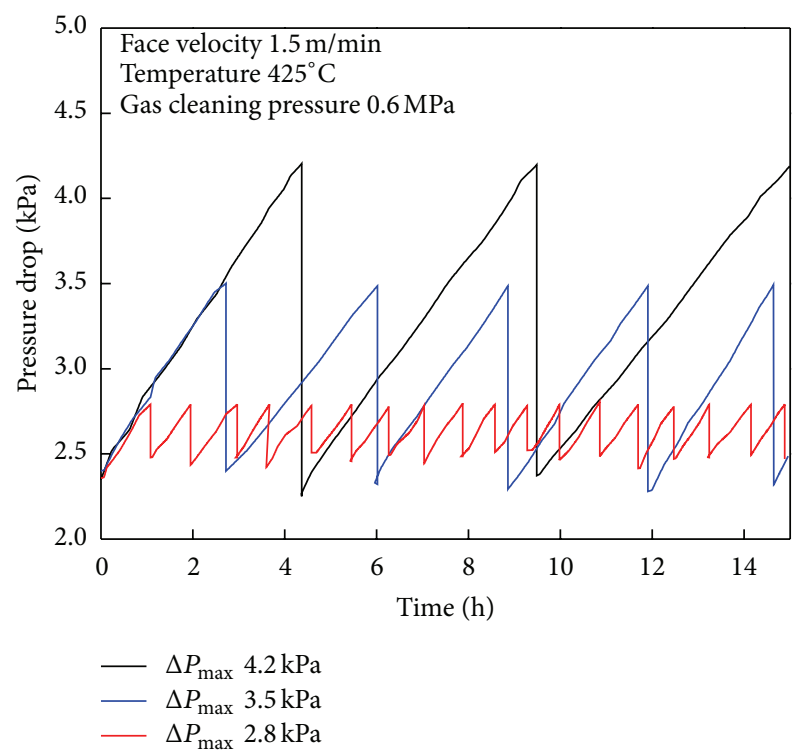

Figure 17: Pressure drop variations for maximum pressure drop of $2.8 \mathrm{kPa}, 3.5 \mathrm{kPa}$, and $4.2 \mathrm{kPa}$.

the filters may be expected since the operation becomes more severe at higher levels of maximum pressure drop.

\section{Conclusions}

A long-term test was performed in a fluid catalytic cracking (FCC) hot gas filtration facility using three sintered metal candle filters under a variety of operating conditions. The effects of operating parameters including face velocity, gas cleaning pressure, pulse duration, and maximum pressure drop were investigated.

Due to the rise of the gas viscosity with temperature, the pressure drop increases when the operating temperature increases at the same face velocity values. There are three reasons for the slow increase in the pressure drop, including the high bulk density of the catalyst particles, the low inlet particle concentration, and the relatively smooth and slippery surface of the filters, which leads to weak adhesion of the dust cake to the filters. The range of inlet particle concentration is from 150 to $165 \mathrm{mg} / \mathrm{Nm}^{3}$. The outlet particle concentration is in the range of $0.71-2.77 \mathrm{mg} / \mathrm{Nm}^{3}$ during the stable operation. The inlet volume median diameters and the outlet volume median diameters of the particles are about $1 \mu \mathrm{m}$ and $2.2 \mu \mathrm{m}$, respectively. The filtration efficiency is more than $99 \%$ when the face velocity is kept in the range of $1.15-1.5 \mathrm{~m} / \mathrm{min}$. At a face velocity of $2.2 \mathrm{~m} / \mathrm{min}$, however, the filtration efficiency is reduced to a value lower than $99 \%$. The cake thickness can be calculated based on the equation of Carman-Kozeny.

The pressure drop across the filters is primarily affected by the face velocity. The appropriate face velocity should not exceed $2.2 \mathrm{~m} / \mathrm{min}$ in this research. Excessive filtration velocity leads to an unfeasible operation. Using gas cleaning pressure higher than $0.6 \mathrm{MPa}$ was not very significant, and the operation was not feasible when the gas cleaning pressure was lower than $0.45 \mathrm{MPa}$. Pulse duration does not show a significant effect on pulse cleaning performance. The frequency of the pulse cleaning decreases with the higher level of maximum pressure drop. However, serious deterioration of the filters may be caused since the operation becomes more severe under a higher maximum pressure drop. In general, the study in this paper shows that the sintered metal fiber filter is suitable for industrial application due to the good performance and high efficiency observed in the experiments. The results are very useful for the next research. The main purposes of the next research are to reduce the emissions to the atmosphere according to the progressively more stringent emission standards and to protect downstream equipment from erosion. We will discuss the long-term operation data in detail later in the next paper.

\section{Nomenclature}

$\begin{array}{ll}C: & \text { Carman-Kozeny constant }(C=180) \\ d_{v}: & \text { Diameter of sphere having the same } \\ & \text { volume as the particle }(\mathrm{m}) \\ h: & \text { Dust cake thickness }(\mathrm{m}) \\ L: & \text { Effective filter length }(\mathrm{m}) \\ m_{\text {cake }}: & \text { Cake mass }(\mathrm{kg}) \\ \Delta p_{B}: & \text { Initial pressure drop }(\mathrm{Pa}) \\ \Delta p_{\mathrm{max}}: & \text { Maximum pressure drop }(\mathrm{Pa}) \\ R_{i}: & \text { Radius of the clean filter }(\mathrm{m}) \\ T: & \text { Operating temperature }\left({ }^{\circ} \mathrm{C}\right) \\ U: & \text { Face velocity }(\mathrm{m} / \mathrm{s}) \\ \varepsilon: & \text { Cake porosity } \\ \phi: & \text { Particle sphericity } \\ \mu: & \text { Dynamic viscosity of gas at filter operating } \\ & \text { temperature }(\mathrm{Pa} \cdot \mathrm{s}) \\ \rho_{B}: & \text { Bulk density of the particles }\left(\mathrm{kg} / \mathrm{m}^{3}\right) .\end{array}$

\section{Conflict of Interests}

The authors declare that there is no conflict of interests regarding the publication of this paper.

\section{Acknowledgments}

The authors acknowledge the sintered metal candle filters provided by Bekaert Corporation Belgium and the experiment assistance by PetroChina Changqing Petrochemical Company.

\section{References}

[1] S. Ito, T. Tanaka, and S. Kawamura, "Changes in pressure loss and face velocity of ceramic candle filters caused by reverse cleaning in hot coal gas filtration," Powder Technology, vol. 100, no. 1, pp. 32-40, 1998.

[2] R. A. Newby, T. E. Lippert, M. A. Alvin, G. J. Burck, and Z. N. Sanjana, "Status of Westinghouse hot gas filters for coal and biomass power systems," Journal of Engineering for Gas Turbines and Power, vol. 121, no. 3, pp. 401-408, 1999.

[3] D. H. Smith and G. Ahmadi, "Problems and progress in hot-gas filtration for pressurized fluidized bed combustion (PFBC) and 
integrated gasification combined cycle (IGCC)," Aerosol Science and Technology, vol. 29, no. 3, pp. 163-169, 1998.

[4] S. Hajek and W. Peukert, "Experimental investigations with ceramic high-temperature filter media," Filtration and Separation, vol. 33, no. 1, pp. 29-37, 1996.

[5] H. Sasatsu, N. Misawa, M. Shimizu, and R. Abe, "Predicting the pressure drop across hot gas filter (CTF) installed in a commercial size PFBC system," Powder Technology, vol. 118, no. 1-2, pp. 58-67, 2001.

[6] J. P. K. Seville and R. Clift, Gas Cleaning in Demanding Applications, Edited by J. P. K. Seville, Blackie/Kluwer, London, UK, 1997.

[7] R. A. Meyers, Handbook of Petroleum Refining Processes, McGraw Hill, 2nd edition, 1996.

[8] V. Vasudevan, B. S. J. Kang, and E. K. Jonson, "A study on ash particle distribution characteristics of candle filter surface regeneration at room temperature," US DOE grant No. DEFC26-99FT40203, 2002.

[9] S. D. Sharma, M. Dolan, D. Park et al., "A critical review of syngas cleaning technologies-fundamental limitations and practical problems," Powder Technology, vol. 180, no. 1-2, pp. 115-121, 2008.

[10] P. Kilgallon, N. J. Simms, J. E. Oakey, and I. Boxall, "Metallic filters for hot gas cleaning," Tech. Rep. Coal R239, Power Generation Technology Center, Cranfield University, Cranfield, UK, 2004.

[11] D. B. Purchas and K. Sutherland, Handbook of Filter Media, Elsevier Advanced Technology, New York, NY, USA, 2nd edition, 2002.

[12] S. Jha, R. S. Sekellick, and K. L. Rubow, "Sintered metal hot gas filters," in High Temperature Gas Cleaning, A. Dittler, G. Hemmer, and G. Kasper, Eds., vol. 2, p. 492, 1999.

[13] M. Heim, B. J. Mullins, H. Umhauer, and G. Kasper, "Performance evaluation of three optical particle counters with an efficient "multimodal' calibration method," Journal of Aerosol Science, vol. 39, no. 12, pp. 1019-1031, 2008.

[14] Q. Xu, Z. Ji, and L. Yang, "Performance assessment of high temperature flue gas on-line particle size analyzer," CIESC Journal, vol. 63, no. 11, pp. 3506-3512, 2012.

[15] E. Schmidt and F. Löffler, "Preparation of dust cakes for microscopic examination," Powder Technology, vol. 60, no. 2, pp. 173$177,1990$.

[16] X. Simon, D. Bémer, S. Calle, D. Thomas, and R. Régnier, "Description of the particle puff emitted downstream of different dust separators consecutive to pulse-jet cleaning," Filtration, vol. 5, no. 1, pp. 52-61, 2005.

[17] J. Binnig, J. Meyer, and G. Kasper, "Origin and mechanisms of dust emission from pulse-jet cleaned filter media," Powder Technology, vol. 189, no. 1, pp. 108-114, 2009.

[18] C. Tien and B. V. Ramarao, "Can filter cake porosity be estimated based on the Kozeny-Carman equation?" Powder Technology, vol. 237, pp. 233-240, 2013.

[19] E. Schmidt, "Experimental investigations into the compression of dust cakes deposited on filter media," Filtration and Separation, vol. 32, no. 8, pp. 789-793, 1995. 

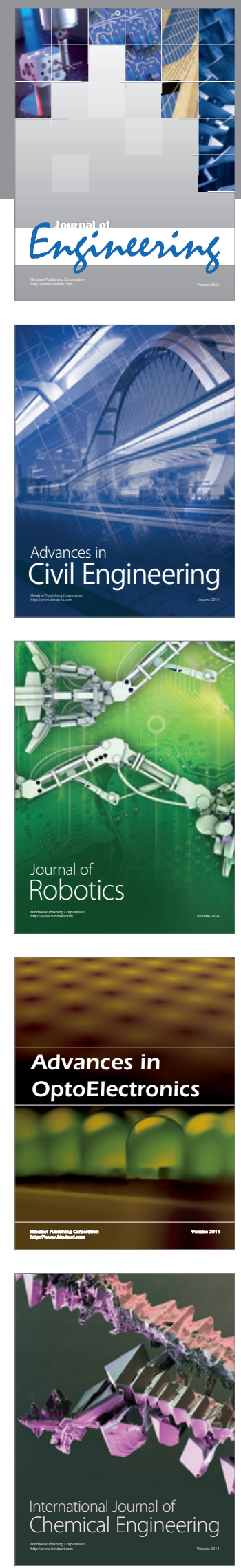

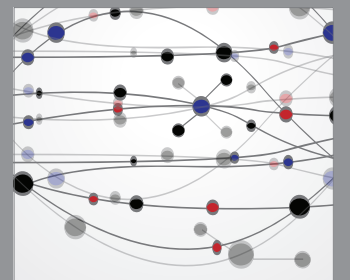

The Scientific World Journal
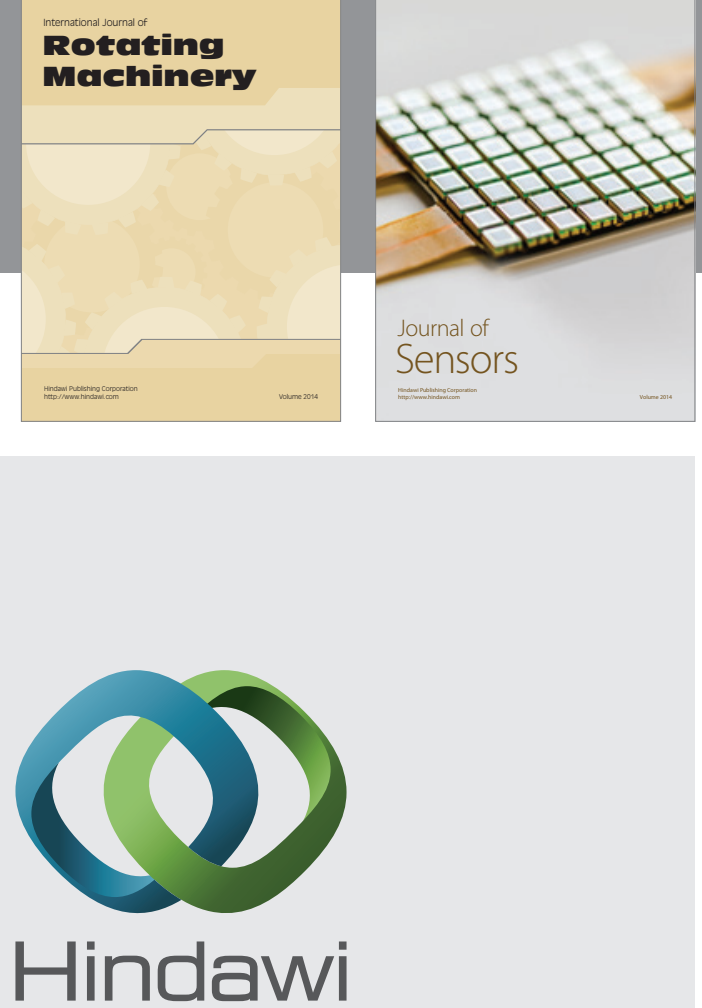

Submit your manuscripts at http://www.hindawi.com
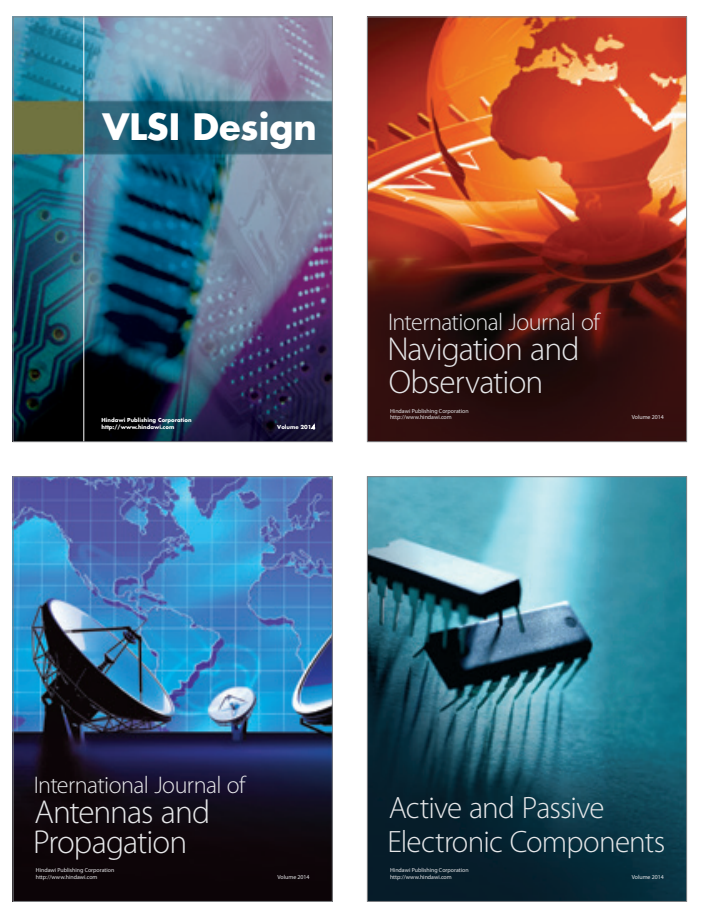
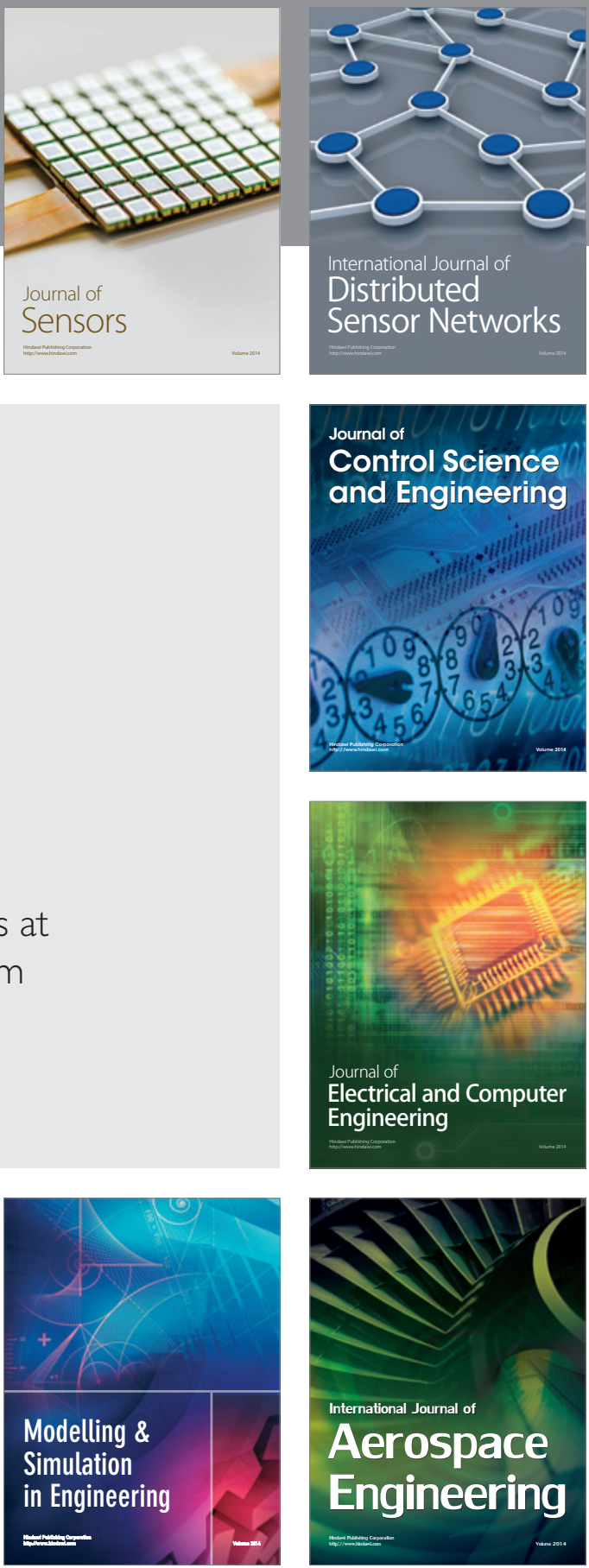

Journal of

Control Science

and Engineering
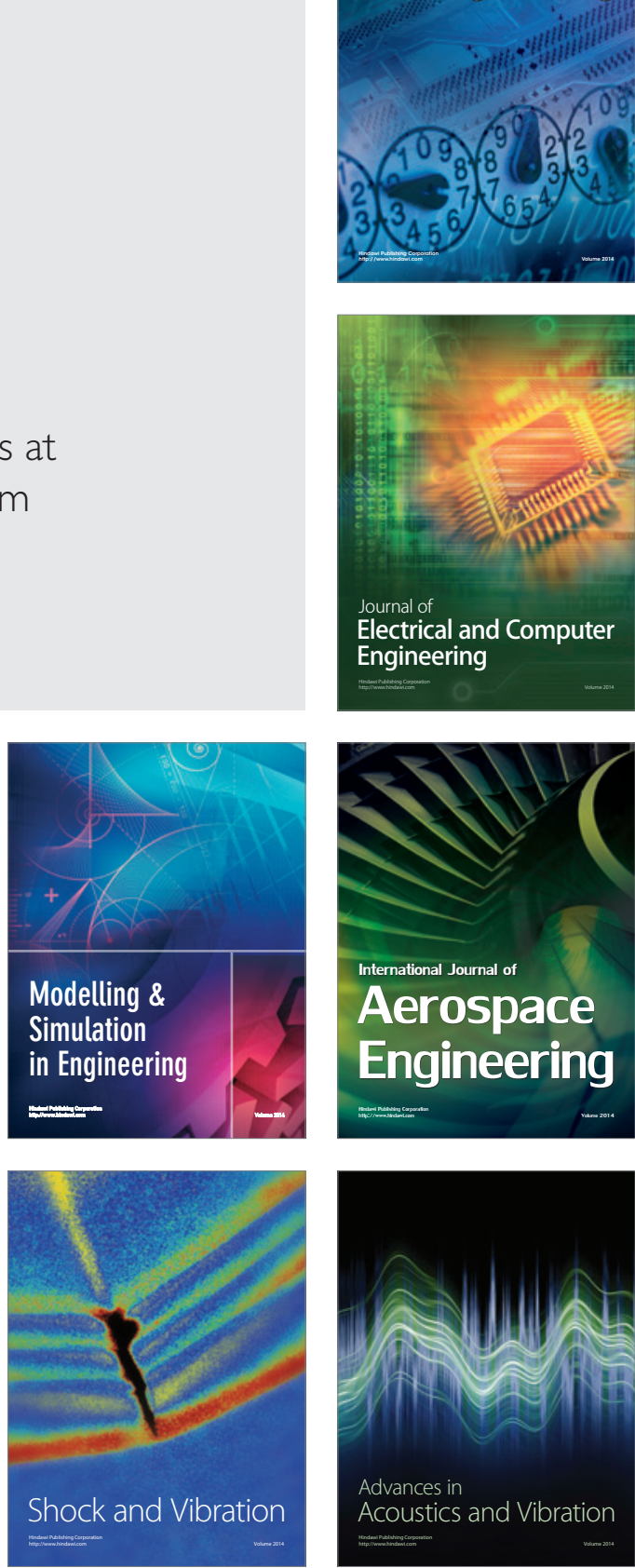